\title{
Analisis gerak teknik dayung dragon boat secara biomekanik
}

\section{Biomechanical dragon boat technique movement analysis}

\author{
Sandi Dwi Triono ${ }^{1}$ \\ ${ }^{1}$ Program studi PJKR, STKIP Pasundan, Cimahi, Jawa Barat, 40512, Indonesia
}

\begin{abstract}
Abstrak
Tujuan penelitian ini adalah untuk mengetahui bagaimana gerakan teknik dan macammacam komponen gerak dayung dragon boat secara biomekanik, yang dimana komponen gerak tersebut terdiri dari posisi siap, posisi masuk, posisi tarik/keluar, posisi kembali, posisi kayuhan dan kecepatan yang dihasilkan. Penelitian ini merupakan penelitian deskriptif. Sampel yang diteliti adalah senior dan junior UKM dayung STKIP Pasundan. Penelitian ini dilakukan sebanyak dua kali, yang pertama analisis komponen gerakan dayung dragon boat, yang kedua mengetahui perbandingan gerakan dayung dragon boat. Meskipun dilakukan tes sebanyak dua kali dan sampel diberi perlakuan yang sama, tidak ada perbedaan antara senior dan junior UKM dayung dengan data hasil analisis tersebut. Dengan hasil dari analisis teknik tersebut diharapkan dapat menjadi suatu sumber pengetahuan yang berguna bagi pelatih, atlet, dan masyarakat.
\end{abstract}

Kata kunci: Dragon Boat, Analisis.

\begin{abstract}
The purpose of this study is to find out how the mechanical movements and various components of the dragon boat paddle motion are biomechanical, wherein the motion component consists of the ready position, entry position, pull / exit position, return position, paddle position and speed produced. This research is descriptive research. The sample studied was senior and junior rowing UKM STKIP Pasundan. This research was conducted twice, the first analysis of the components of the dragon boat paddle movement, the second to know the comparison of the dragon boat paddle movements. Although the tests were carried out twice and the samples were given the same treatment, there was no difference between senior and junior rowing UKM with the data from the analysis. With the results of the analysis of the technique is expected to be a useful source of knowledge for coaches, athletes, and the community.
\end{abstract}

Keywords: Dragon Boat, Analysis.

\section{PENDAHULUAN}

Olahraga adalah salah satu upaya dalam peningkatan kualitas manusia indonesia yang diarahkan pada pembentukan watak dan kepribadian (Zuzana, 2015). Adapun maksud dan tujuan dari kegiatan olahraga itu sendiri salah satunya adalah untuk meningkatkan prestasi.

Di dalam olahraga dayung dragon boat pada ukm dayung STKIP Pasundan menurut penelitian saya terdapat beberapa perbedaan dalam segi teknik senior dan junior, yaitu gerakan teknik posisi siap, posisi sudut kayuhan, dan kecepatan yang dihasilkan. 
Seperti posisi siap tangan yang menggenggam pegangan dayung bagian atas berada di atas kepala dan posisi tangan bawah berada lurus di depan mata sambil menggenggam batang dayung dengan jarak $37 \mathrm{~cm}$ dari daun dayung. Saat itu juga posisi dayung tegak lurus di atas air serta posisi bahu. Kemudian posisi memegang tongkat dayungan dengan jarak tinggi 1 meter dan perlu disadari bahwa pemberian teknik yang salah dapat berpengaruh buruk pada prestasi atlet (Rahmawati, 2013).

Untuk menghasilkan suatu prestasi yang lebih baik pada olahraga dayung Dragon boat diperlukan adanya latihan-latihan terutama latihan teknik mendayung dengan intensitas tinggi yang didalamnya terdapat beberapa aspek penting (Bauer et al., 2018; Brooke, 2015; Hsieh et al., 2012). Gerakan tepat yang diteliti secara biomekanik mampu menghasilkan kualitas gerak yang lebih efektif dan efisien (Hsieh \& Knudson, 2018; Knudson, 2017; Warmenhoven et al., 2019)

Oleh karena itu untuk mengetahui bagaimana gerakan teknik dan macam-macam komponen gerak dayung dragon boat secara biomekanika yang dimana komponen gerak tersebut terdiri dari posisi siap, posisi sudut kayuhan, dan kecepatan. dengan hasil dari analisis teknik tersebut diharapkan dapat menjadi suatu sumber pengetahuan yang berguna bagi pelatih, atlet dan masyarakat.

\section{METODE}

Penelitian ini menggunakan metode deskriptif dimana populasi dalam penelitian ini adalah anggota senior dan junior UKM Dayung STKIP Pasundan Cimahi yang berjumlah 12 orang. Teknik purposive sampling digunakan untuk menentukan sampel penelitian, karena bertujuan agar data yang diperoleh nanatinya lebih repersentatif (Sugiyono, 2017). Maka sampel yang di ambil adalah anggota senior dan junior UKM Dayung yang berjumlah 10 orang. instrumen yang digunakan adalah menggunakan bantuan software dartfish. ini dilakukan dengan cara merekam video menggunakan kamera dari arah samping kanan, kiri, depan, belakang dan atas untuk bisa menganalisa gerakan posisi siap, posisi tongkat, sudut kayuhan dan kecepatan dayung dragon boat secara biomekanika. Dartfish adalah penyedia solusi video yang berbasis di Fribourg $\underline{\text { Swiss. }}$ Perusahaan mengembangkan perangkat lunak video online dan offline untuk 
memungkinkan pengguna melihat, mengedit, dan menganalisis video untuk penggunaan individu dan perusahaan.

\section{HASIL DAN PEMBAHASAN}

\section{Hasil}

Pengolahan data dimulai dengan menskorkan skala dan mentabulasi data Data ini merupakan bentuk rangkaian gerak mendayung yang dilakukan oleh subyek penelitian selama pengambilan data berlangsung. Beberapa hasil analisis yang disajikan dalam penelitian ini antara lain:

\section{Tabel 1}

Hasil Analisis Rangkaian Gerak Mendayung

\begin{tabular}{|c|c|c|c|c|c|}
\hline No & Keterangan & Posisi Siap & Posisi Masuk & $\begin{array}{c}\text { Posisi Tarik / } \\
\text { Keluar }\end{array}$ & Posisi Kembali \\
\hline 1 & $\begin{array}{l}\text { Posisi tangan } \\
\text { atas }\end{array}$ & $\begin{array}{l}\text { Lurus diatas } \\
\text { kepala }\end{array}$ & Lurus diatas kepala & $\begin{array}{l}\text { Lurus didepan } \\
\text { dada }\end{array}$ & $\begin{array}{l}\text { Mengangkat } \\
\text { dayung kembali } \\
\text { keposisi siap }\end{array}$ \\
\hline 2 & $\begin{array}{l}\text { Posisi tangan } \\
\text { bawah }\end{array}$ & $\begin{array}{l}\text { Lurus didepan } \\
\text { mata }\end{array}$ & $\begin{array}{l}\text { Lurus menjatuhkan } \\
\text { dayung kedalam air }\end{array}$ & $\begin{array}{l}\text { Menarik dayung } \\
\text { kebelakang }\end{array}$ & $\begin{array}{l}\text { Membawa } \\
\text { dayung kembali } \\
\text { keposisi siap }\end{array}$ \\
\hline 3 & $\begin{array}{l}\text { Posisi } \\
\text { pinggang }\end{array}$ & $\begin{array}{l}\text { Condong } \\
\text { kedepan serong } \\
\text { kedalam }\end{array}$ & $\begin{array}{l}\text { Condong kedepan } \\
\text { serong kedalam }\end{array}$ & $\begin{array}{l}\text { Putar keluar } \\
\text { menarik dayung }\end{array}$ & $\begin{array}{l}\text { Putar kedalam } \\
\text { kembali ke } \\
\text { posisi siap }\end{array}$ \\
\hline 4 & Posisi dayung & $\begin{array}{l}\text { Tegak lurus } \\
\text { diatas } \\
\text { permukaan air }\end{array}$ & $\begin{array}{l}\text { Daun dayung } \\
\text { masuk kedalam air }\end{array}$ & $\begin{array}{l}\text { Daun dayung } \\
\text { keluar dari air }\end{array}$ & $\begin{array}{l}\text { Daun dayung } \\
\text { diatas } \\
\text { permukaan air }\end{array}$ \\
\hline
\end{tabular}

Tabel 2

Hasil Rata-rata Sudut Gerakan

\begin{tabular}{cccc}
\hline No & Jenis Gerakan & Sudut & Simpangan Baku \\
\hline $\mathbf{1}$ & Posisi Siap & $42.2^{\circ}$ & $0.92^{\circ}$ \\
$\mathbf{2}$ & Sudut Kayuhan & $40^{\circ}$ & $1.22^{\circ}$ \\
$\mathbf{3}$ & Posisi Masuk & $42^{\circ}$ & $1.04^{\circ}$ \\
$\mathbf{4}$ & Posisi Tarik Keluar & $129^{\circ}$ & $2.14^{\circ}$ \\
$\mathbf{5}$ & Posisi Kembali & $124.1^{\circ}$ & $6.65^{\circ}$ \\
\hline
\end{tabular}

Berdasarkan data hasil tabel 2 diatas terdapat hasil, posisi siap dari data yang diambil diperoleh hasil rata-rata sebesar $42.2^{\circ}$, Sudut kayuhan dari data yang diambil diperoleh hasil rata-rata sebesar $40^{\circ}$, posisi masuk dari data yang diambil diperoleh hasil 
rata-rata sebesar $42^{\circ}$, posisi tarik dan keluar dari data yang diambil diperoleh hasil ratarata sebesar $129^{\circ}$, posisi kembali dari data yang diambil diperoleh hasil rata-rata sebesar $124.1^{\circ}$.

Kecepatan Dayung

$$
\begin{aligned}
\omega & =\boldsymbol{\Theta} / \mathbf{t} \\
\omega & =\text { Kecepatan } \\
\boldsymbol{\Theta} & =\text { Sudut }^{\circ} \\
\mathbf{T} & =\text { Waktu } \\
\Theta & =58^{\circ} \mathrm{rad}, \quad \mathrm{t}=1 \mathrm{~s} \\
\omega & =58 / 1 \\
& =58 \mathrm{rad} / \mathrm{s}^{2}
\end{aligned}
$$

\begin{tabular}{|c|c|c|c|c|c|c|}
\hline No & Nama & $\begin{array}{l}\text { Posisi } \\
\text { Siap }\end{array}$ & $\begin{array}{c}\text { Sudut } \\
\text { Kayuhan }\end{array}$ & $\begin{array}{l}\text { Posisi } \\
\text { Masuk }\end{array}$ & $\begin{array}{l}\text { Posisi Tarik } \\
\text { Keluar }\end{array}$ & $\begin{array}{c}\text { Posisi } \\
\text { Kembali }\end{array}$ \\
\hline 1 & Ridwan & 41 & 40 & 42 & 131 & 130 \\
\hline 2 & Syifa fauziah & 42 & 40 & 42 & 129 & 129 \\
\hline 3 & Dade hilman $\mathrm{f}$ & 43 & 41 & 43 & 127 & 129 \\
\hline 4 & Geget nenda $p$ & 42 & 40 & 41 & 131 & 113 \\
\hline 5 & Amrul hayat & 43 & 41 & 43 & 130 & 131 \\
\hline 6 & Efa yuliani & 42 & 40 & 42 & 131 & 123 \\
\hline 7 & Habibi & 42 & 41 & 43 & 128 & 122 \\
\hline 8 & Cahyo nurkolis & 43 & 39 & 44 & 125 & 120 \\
\hline 9 & Dewi & 42 & 38 & 43 & 130 & 115 \\
\hline 10 & Dianty & 42 & 40 & 42 & 128 & 129 \\
\hline \multicolumn{2}{|c|}{ Rata-rata } & 42,2 & 40 & 42,5 & 129 & 124,1 \\
\hline \multicolumn{2}{|c|}{ Simpangan Baku } & 0,92 & 1,22 & 1,04 & 2,14 & 6,65 \\
\hline
\end{tabular}

Jadi:

$$
\begin{aligned}
\mathbf{V} & =\mathbf{r} \cdot \boldsymbol{\omega} \mathrm{V}=1,5 \times 58 \\
& =87 \mathrm{~m} / \mathrm{s}
\end{aligned}
$$

Dari data yang diambil diperoleh hasil rata-rata sebesar $87 \mathrm{~m} / \mathrm{s}$

Tabel 3

Data Hasil Analisis Teknik Gerak Dayung Dragon Boat Secara Biomekanik

\section{Pembahasan}

Berdasarkan hasil analisa penelitian dengan mengunakan bantuan aplikasi software darthfish. 


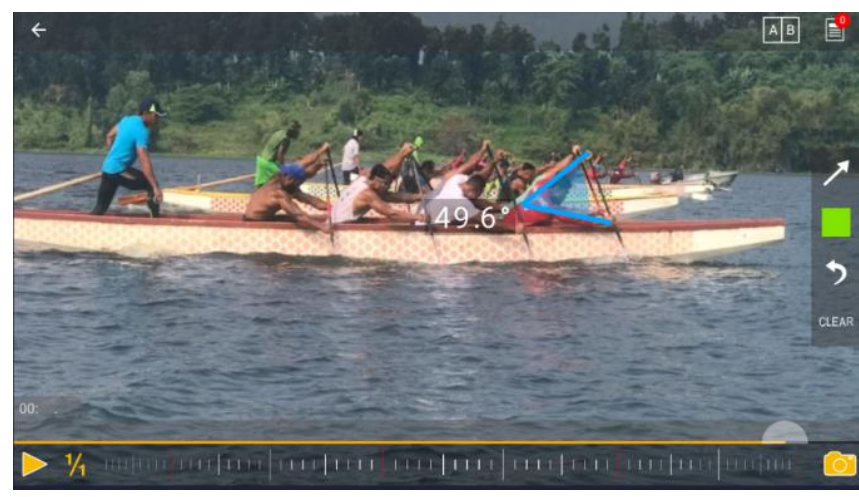

Gambar 1

Tampilan aplikasi ketika mengedit/menganalisis video

Analisis Dartfish adalah software yang pada intinya diperlukan seseorang dalam mengukur sesuatu yang tidak dapat dilihat oleh kejelian mata. Software ini dilengkapi dengan sebuah kamera, software ini dapat menganalisis gerakan tetapi kecenderungannya kualitatif, manipulasi dengan variabel gerakan juga tidak dapat dilakukan secara langsung. Dartfish dapat dipakai untuk melambatkan sebuah gerakan dan menghentikan gerakan, pengukuran panjang, sudut segmen tubuh, kecepatan dan percepatan gerak serta waktunya. Simulasi ini bisa dilakukan tetapi tidak langsung. Hasil rekaman gambar selanjutnya dapat ditransfer ke dalam komputer, sehingga rekaman gambar videonya dapat dianalisis sesuai kehendak pengamat yang telah diuraikan diatas, maka dapat ditemukan jawaban dari penelitian yaitu:

Tidak ada perbedaan antara senior dan junior di UKM Dayung dengan hasil data pada posisi siap posisi lengan atas berada di atas kepala dan genggaman tangan bawah lurus didepan mata membentuk sudut $42,2^{\circ}$ dan jarak pegangan dengan daun dayung sebesar $37 \mathrm{~cm}$, dengan posisi bahu dan pinggang condong ke depan dan agak sedikit serong ke dalam membentuk sudut $30^{\circ}$ antara pinggang dengan bibir perahu. Dengan demikian diperoleh posisi siap dengan jangkauan yang jauh tetapi dengan posisi dayung yang tegak agar saat dayung di masukkan ke dalam air tidak miring.

Pada posisi masuk tangan atas tetap di atas kepala, tetapi tangan bawah memasukkan daun dayung ke dalam air dengan posisi pinggang dan bahu tetap condong ke depan sedikit membungkuk ke bawah agar tangan bawah lebih mudah memasukkan daun dayung ke dalam air, saat itu juga membentuk sudut $42^{\circ}$ antara tangan atas dan bawah. Dari keterangan di atas gerakan posisi masuk model ini lebih mudah, karena posisi ini dapat menjangkau banyak air ketika akan menarik dayung ke belakang/keluar dari air. 
Kemudian pada posisi tarik dan keluar, genggaman tangan atas berada lurus di depan dada dan tangan bawah menarik dayung ke belakang/keluar di atas permukaan air yang membentuk sudut siku lengan sebesar $129^{\circ}$ dan jarak antara daun dayung dengan perahu sebesar $25 \mathrm{~cm}$, saat itu juga bahu dan pinggang diputar ke arah luar (bibir perahu) dan membantu tangan untuk menarik dayung yang membentuk sudut antara pinggang dan bibir perahu sebesar $90^{\circ}$. Dari ketarangan di atas dapat disimpulkan bahwa gerakan menarik dan keluar tersebut sangat efisien, karena tidak hanya tangan yang menarik dayung tetapi pinggang dan bahu juga membantu menarik dayung tersebut, dengan demikian diperoleh tenaga tarikan yang besar dan luncuran perahu yang jauh.

Pada posisi kembali, posisi tangan atas mengangkat dayung ke atas kembali ke posisi siap, sedangkan tangan bawah menggiring daun dayung kembali ke depan (posisi siap) dengan daun dayung berada di atas permukaan air dan diperoleh sudut siku lengan bawah sebesar $124,1^{\circ}$ dan jarak daun dayung dengan perahu sebesar $31 \mathrm{~cm}$. Saat itu juga bahu dan pinggang kembali condong ke depan kembali membentuk gerakan posisi siap. Dengan gerakan ini pedayung lebih mudah, terarah, cepat dan tepat untuk menggerakkan dayung kembali pada posisi semula (posisi siap). sedangkan Kalkulasi data untuk kecepatan dayung diperoleh data rata-rata $87 \mathrm{~m} / \mathrm{s}$.

Analisis gerak mempunyai fungsi teknis metodologis, yaitu cara-cara ilmiah yang digunakan untuk mengumpulkan, menyusun, menyajikan dan menganalisis data penelitian. Hasil analisis memberikan dasar-dasar yang dapat dipertanggung-jawabkan dalam menarik kesimpulan penelitian secara benar, layak dan teliti. Serta gerak umum lainnya (gerak gabungan), yang dapat terjadi (Budiwanto, 2017). Bukan hanya gerak benda yang ada di darat, akan tetapi juga gerak benda yang ada pada media lain, seperti air, udara, dan bahkan gerak benda yang ada pada ruang hampa udara. Analisis biomekanika secara kuantitatif meliputi pengukuran-pengukuran berbagai variabel biomekanis (Bambang, 2014). Beberapa variabel tersebut meliputi timing (ketepatan waktu gerak), kinematika (posisi, perpindahan, kecepatan, percepatan), atau kinetika (gaya (Force), energi (E), Usaha (work), dan (Power). Untuk dapat melakukan pengukuran terhadap variabel-variabel tersebut, kita membutuhkan alat khusus untuk itu (Kurniawan, 2007).

Teknik adalah cara sistematis mengajarkan sesuatu, teknik merupakan suatu kiat, siasat, atau penemuan yang digunakan untuk menyelesaikan serta menyempurnakan suatu ttujuan langsung (Wassid \& Sunendar, 2014). Jika dikaitkan dengan pelajaran olahraga teknik berarti cara-cara yang dilakukan seseorang untuk mempraktekkan suatu metode sesuai dengan olahraga yang bersangkutan. 


\section{KESIMPULAN}

Berdasarkan hasil penelitian dan pembahasan mengenai analisis teknik gerak dayung dragon boat secara biomekanik memiliki pengaruh terhadap kecepatan dayung dragon boat yang diteliti.

Posisi siap dari data yang diambil diperoleh hasil rata-rata sebesar 42.2 o, Sudut kayuhan dari data yang diambil diperoleh hasil rata-rata sebesar $40 \mathrm{o}$, posisi masuk dari data yang diambil diperoleh hasil rata-rata sebesar $42 \mathrm{o}$, posisi tarik dan keluar dari data yang diambil diperoleh hasil rata-rata sebesar 129 o, posisi kembali dari data yang diambil diperoleh hasil rata-rata sebesar 124.10.

Tidak ada perbedaan antara senior dan junior di UKM Dayung, dengan hasil data pada posisi siap, sudut kayuhan diperoleh hasil rata-rata sebesar 40 o dan kecepatan yang dihasilkan senior dan junior rata-rata $59 \mathrm{~m} / \mathrm{s}$. Posisi lengan atas berada di atas kepala dan genggaman tangan bawah lurus didepan mata membentuk sudut 42,2o dan jarak pegangan dengan daun dayung sebesar $37 \mathrm{~cm}$, dengan posisi bahu dan pinggang condong ke depan dan agak sedikit serong ke dalam membentuk sudut 30o antara pinggang dengan bibir perahu. Dengan demikian diperoleh posisi siap dengan jangkauan yang jauh tetapi dengan posisi dayung yang tegak agar saat dayung di masukkan ke dalam air tidak miring.

\section{DAFTAR PUSTAKA}

Bambang, K.S. (2014). Biomekanika olahraga. Jakarta : kemenpora.

Bauer, P., Zeissler, S., Walscheid, R., Frech, T., \& Hillebrecht, A. (2018). Acute effects of high-intensity exercise on hematological and iron metabolic parameters in elite male and female dragon boating athletes. Physician and Sportsmedicine, 46(3), 335-341. https://doi.org/10.1080/00913847.2018.1482187

Brooke, M. (2015). Fongzi, dragons and corporate culture: An analysis of corporate dragon-boat paddlers' motivations. Asia Pacific Journal of Sport and Social Science, 4(2), 99-112. https://doi.org/10.1080/21640599.2015.1060037

Budiwanto, Setyo. (2017). Metode statistika untuk mengolah data keolahragaan. Universitas Negeri Malang.

Hsieh, C. T., \& Knudson, D. (2018). Important learning factors in high- and lowachieving students in undergraduate biomechanics. Sports Biomechanics, 17(3), 361-370. https://doi.org/10.1080/14763141.2017.1347194

Hsieh, C. T., Mache, M., \& Knudson, D. (2012). Does student learning style affect performance on different formats of biomechanics examinations? Sports Biomechanics, 11(1), 108-119. https://doi.org/10.1080/14763141.2011.637128 
Knudson, D. (2017). Confidence crisis of results in biomechanics research. Sports Biomechanics, 16(4), 425-433. https://doi.org/10.1080/14763141.2016.1246603

Kurniawan, Faidillah. (2007). Analisis secara biomekanika teknik gerak serang dalam anggar.

Rahmawati, Agsa Nuzul. (2013). Analisis teknik dayung pada atlet dayung badjoel dragon boat surabaya. Surabaya: Jurnal UNESA, vol 1.

Sugiyono. (2017). Metode Penelitian Kuantitatif, Kualitatif dan R\&D. Alfabeta.

Warmenhoven, J., Cobley, S., Draper, C., Harrison, A., Bargary, N., \& Smith, R. (2019). Considerations for the use of functional principal components analysis in sports biomechanics: examples from on-water rowing. Sports Biomechanics, 18(3), 317341. https://doi.org/10.1080/14763141.2017.1392594

Wassid, Iskandar \& Sunendar, Dadang. (2014). Strategi Pembelajaran Bahasa Remaja. Bandung: Rosda Karya.

Zuzana, Melly. (2015). Konstribusi daya tahan kekuatan otot lengan dan kelentukan terhadap kemampuan mendayung dragon jarak 500 meter atlet dayung kabupaten padang pariaman. Jurnal Universitas Negeri Malang. 